\title{
Yield of Universal Testing for DNA Mismatch Repair Protein Deficiency in Colorectal Carcinoma From an Australian Community-based Practice
}

\author{
Gregory C. Miller, Mark L. Bettington, lan S. Brown, Christophe Rosty \\ Envoi Specialist Pathologists, 5/38 Bishop Street, Kelvin Grove QLD, Australia. Phone: +6173552 \\ 6400; Fax: +61 73352 4266; Email: c.rosty@uq.edu.au
}

\begin{abstract}
Lynch syndrome is the most common cause of inherited colorectal carcinoma (CRC). Testing all newly diagnosed CRC for MMR protein deficiency, known as universal testing, has recently emerged as the preferred approach to identify potential Lynch syndrome individuals. All newly diagnosed CRCs were screened for MMR protein expression by immunohistochemistry. A 2-step approach was used: PMS2 and MSH6 testing followed by the testing of the respective MMR protein partner if one of the proteins is lost. We retrospectively searched our pathology database for MMR protein expression results across a 5-year period (2012-2016) when universal testing was performed. Clinical and pathological data were extracted from the pathology report. A total of 2077 consecutive CRCs were tested for MMR protein expression. Mean age at diagnosis was 68.4 years. MMR protein deficiency was identified in 399 cases (19.2\%). The vast majority of CRC with MLH1/PMS2 loss were diagnosed in patients older than 70 years (84\%), most of them are likely to be secondary to sporadic MLH1 methylation. MMR protein deficiency patterns suggestive of a defect in MSH2, MSH6 or PMS2 comprised 42 cases, of which 37 were found in individuals aged 50 years or older. CRCs with MSH2/MSH6 loss were most commonly found in patients older than 70 years (57\%). In summary, universal testing for MMR protein deficiency in CRC identifies abnormal patterns of expression suggestive of Lynch syndrome in all age groups. Further studies are needed to demonstrate the actual rate of Lynch syndrome individuals identified from this initial screening.
\end{abstract}

\section{Introduction}

In Australia, colorectal carcinoma (CRC) is the second most common cancer with a lifetime risk by age 75 years of 1 in 23 and is the second leading cause of death from cancer (1 in 48 by age 85$).{ }^{1}$ One way to reduce the mortality associated with CRC is the early detection of high risk individuals who then undergo additional screening. Lynch syndrome is the most common cause of inherited CRC, responsible for $3 \%$ of all incident cases. ${ }^{2}$ Lynch syndrome is an autosomal dominant disorder, defined by the identification of a pathogenic germline mutation in one of the DNA mismatch repair (MMR) genes $\mathrm{MLH1}, \mathrm{MSH}$, $M S H 6$, or PMS2 or in EPCAM, a gene upstream of $M S H 2$. Affected individuals have a cumulative risk of $\mathrm{CRC}$ at 70 years of $30-50 \%$ for MLH1 or MSH2 mutation carriers and of $10-20 \%$ for MSH6 or PMS2 mutation carriers. ${ }^{3,4}$ Lynch syndrome individuals also have an increased risk of developing cancers of the endometrium, urinary tract, pancreas, hepatobiliary tract, stomach, small intestine and ovaries.

Among various screening strategies advocated, testing all newly diagnosed CRC for MMR protein expression by immunohistochemistry has emerged as the preferred approach to identify potential Lynch syndrome individuals.
This reflex testing strategy, commonly named universal testing, is now recommended by multiple guidelines and professional medical organisations. ${ }^{5-7}$ The sensitivity of universal testing for detecting Lynch syndrome is close to $100 \%^{8}$ and, when compared with testing restricted to patients younger than 50 years at CRC diagnosis or fulfilling Bethesda criteria, can detect nearly twice as many individuals with Lynch syndrome with a favourable costeffectiveness ratio per life-year saved. ${ }^{9}$

In this study, we investigated the proportion of CRC with abnormal MMR protein expression over a 5-year period when universal testing was performed in a communitybased gastrointestinal pathology practice. Our aims were 1) to report the number of MMR deficient CRC cases using universal testing and 2) to identify possible Lynch syndrome individuals who would have been missed if a more restricted testing strategy was used.

\section{Materials and methods}

Envoi Specialist Pathologists is a community-based histopathology practice in Brisbane, Queensland, Australia, that specialises in gastrointestinal pathology. Since 2012, all newly diagnosed CRCs have been screened for MMR protein expression by immunohistochemistry. To 
bioRxiv preprint doi: https://doi.org/10.1101/270322; this version posted February 23, 2018. The copyright holder for this preprint (which was not certified by peer review) is the author/funder, who has granted bioRxiv a license to display the preprint in perpetuity. It is made available under aCC-BY-NC-ND 4.0 International license.

Universal Testing for Lynch Syndrome

retrospectively select the study cases, we searched our pathology database for MMR protein immunohistochemistry results using the term "MSH6" as key word, between January $1^{\text {st }} 2012$ and December 31st 2016. Duplicate entries (those with immunohistochemistry performed on both biopsy and resection specimens) were removed. Clinical and pathological data were extracted from the pathology report, including age at diagnosis, sex, CRC location and TNM stage.

Identification of immunohistochemical expression of MMR proteins was performed in a 2-step approach. Firstly, each CRC was tested for PMS2 and MSH6 expression. CRCs with the normal retained expression of both PMS2 and MSH6 were classified as MMR-proficient. If loss of expression of either PMS2 or MSH6 was identified, the corresponding binding partner was subsequently tested (MLH1 for initial PMS2 loss, MSH2 for initial MSH6 loss). Immunohistochemistry was performed on Dako autostainer with ready to use antibodies from Dako (Carpinteria, CA, USA): clone ES05 for MLH1, clone FE11 for MSH2, clone EP51 for PMS2 and clone EP49 for MSH6. CRCs with loss of expression of at least one MMR protein in carcinoma cells were classified as MMR-deficient. In cases with synchronous or metachronous carcinomas, each tumour was separately tested.

\section{Results}

A total of 2077 consecutive CRCs with MMR protein expression results were identified from 2016 patients. Mean age at CRC diagnosis was 68.4 (median 70; range $18-96$ years). Females comprised $45.5 \%$ of incident cases. MMR protein deficiency was identified in 399 cases (19.2\%). The detailed results of the abnormal immunohistochemical patterns are displayed in Table 1, stratified by age groups.

\begin{tabular}{lccccc}
\hline & All ages & $<50$ years & $50-59$ years & $60-69$ years & $\geq 70$ years \\
\hline MMR proficient & 1678 & $171(10 \%)$ & $274(16 \%)$ & $489(29 \%)$ & $744(44 \%)$ \\
\hline MLH1/PMS2 & 357 & $13(4 \%)$ & $11(3 \%)$ & $34(9 \%)$ & $299(84 \%)$ \\
MSH2/MSH6 & 23 & $2(9 \%)$ & $1(4 \%)$ & $7(30 \%)$ & $13(57 \%)$ \\
MSH6 & 12 & $3(25 \%)$ & $3(25 \%)$ & $4(33 \%)$ & $2(17 \%)$ \\
PMS2 & 7 & $2(29 \%)$ & $0(0 \%)$ & $2(29 \%)$ & $3(42 \%)$ \\
\hline
\end{tabular}

Table 1. Number of MMR-proficient and MMR-deficient colorectal carcinomas by pattern of MMR protein loss and age groups

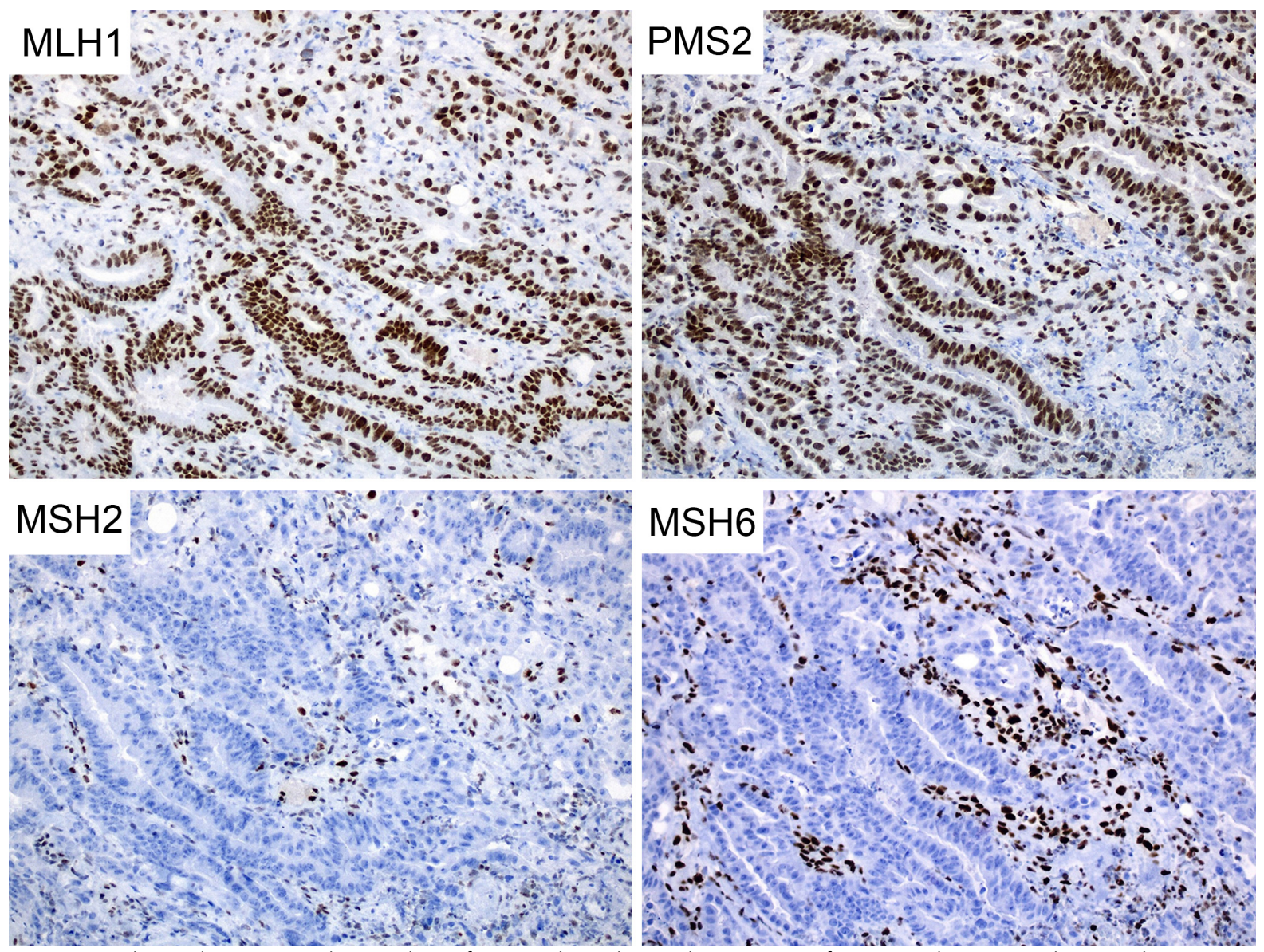

Figure 1. Colorectal carcinoma showing loss of immunohistochemical expression of MSH2 and MSH6, and retained expression of MLH1 and PMS2. 
bioRxiv preprint doi: https://doi.org/10.1101/270322; this version posted February 23, 2018. The copyright holder for this preprint (which was not certified by peer review) is the author/funder, who has granted bioRxiv a license to display the preprint in perpetuity. It is made available under aCC-BY-NC-ND 4.0 International license.

Universal Testing for Lynch Syndrome

\begin{tabular}{|c|c|c|c|c|c|}
\hline & $\begin{array}{l}\text { All MMR-deficient } \\
\qquad \mathrm{N}=399\end{array}$ & $\begin{array}{c}\text { MLH1/PMS2 } \\
\mathrm{N}=357\end{array}$ & $\begin{array}{c}\mathrm{MSH} 2 / \mathrm{MSH} 6 \\
\mathrm{~N}=23\end{array}$ & $\begin{array}{l}\mathrm{MSH} 6 \\
\mathrm{~N}=12\end{array}$ & $\begin{array}{c}\text { PMS2 } \\
\mathrm{N}=7\end{array}$ \\
\hline Age, yrs (Median, Q1-Q3) & $78(71.75-84)$ & $79(73-84)$ & $71(62.5-78)$ & $58.5(48-68)$ & $61(32-76)$ \\
\hline Female & 261 (65\%) & $243(68 \%)$ & $6(26 \%)$ & 7 (58\%) & 5 (71\%) \\
\hline \multicolumn{6}{|l|}{ Tumour location } \\
\hline Proximal colon & $344(86 \%)$ & 317 (89\%) & $16(70 \%)$ & $5(42 \%)$ & $6(86 \%)$ \\
\hline Distal colon & $38(10 \%)$ & 32 (9\%) & $3(13 \%)$ & $3(25 \%)$ & $0(0 \%)$ \\
\hline Rectum & 17 (4\%) & $8(2 \%)$ & $4(17 \%)$ & $4(33 \%)$ & $1(14 \%)$ \\
\hline \multicolumn{6}{|l|}{ Histologic type } \\
\hline Adenocarcinoma & 298 (75\%) & $266(74 \%)$ & 15 (65\%) & $11(92 \%)$ & $6(86 \%)$ \\
\hline Mucinous carcinoma & $84(21 \%)$ & $75(21 \%)$ & 7 (31\%) & 1 (8\%) & $1(14 \%)$ \\
\hline Signet ring cell & $10(2 \%)$ & $10(3 \%)$ & $0(0 \%)$ & $0(0 \%)$ & $0(0 \%)$ \\
\hline Medullary carcinoma & $7(2 \%)$ & $6(2 \%)$ & $1(4 \%)$ & $0(0 \%)$ & $0(0 \%)$ \\
\hline \multicolumn{6}{|l|}{ Differentiation } \\
\hline Well/Moderate & 207 (52\%) & 179 (50\%) & 14 (61\%) & $9(75 \%)$ & $5(71 \%)$ \\
\hline Poor & 192 (48\%) & $178(50 \%)$ & 9 (39\%) & $3(25 \%)$ & $2(29 \%)$ \\
\hline \multicolumn{6}{|l|}{ Tumour stage, AJCC } \\
\hline 1 & $106(27 \%)$ & $88(25 \%)$ & $14(61 \%)$ & $4(33)$ & $0(0 \%)$ \\
\hline II & 137 (34\%) & $125(35 \%)$ & $4(17 \%)$ & $4(33)$ & $4(57 \%)$ \\
\hline III & $68(17 \%)$ & 64 (18\%) & 3 (13\%) & $1(8)$ & $0(0 \%)$ \\
\hline IV & 10 (2.5\%) & 10 (3\%) & $0(0 \%)$ & $0(0)$ & $0(0 \%)$ \\
\hline missing & 78 (19.5\%) & $70(20 \%)$ & $2(9 \%)$ & $3(25 \%)$ & 3 (43\%) \\
\hline
\end{tabular}

Table 2. Clinicopathologic features of MMR-deficient colorectal carcinomas by pattern of MMR protein loss

The vast majority of CRC with MLH1/PMS2 loss were diagnosed in patients aged 70 years or older (84\%). In 8 cases with MLH1/PMS2 loss, loss of MSH6 expression was also present. MMR protein deficiency patterns suggestive of a defect in MSH2, MSH6 or PMS2 were seen in 42 cases, of which 35 were found in individuals aged 50 years or older (Figure 1). CRCs with MSH2/MSH6 loss were most commonly found in patients older than 70 years (57\%). The clinicopathological features of MMR-deficient cases are listed in Table 2. CRCs with MLH1/PMS2 loss were diagnosed more frequently in the proximal colon of females at a median age of 79 years. Cases with MSH2/MSH6 loss were characterized by male predominance, older age at diagnosis (median 71 years) compared with MSH6 loss or PMS2 loss, highest frequency of mucinous carcinoma (31\%) and of stage I disease (61\%). The rectum was most frequently involved in MSH6deficient cases, compared with other MMR-deficient cases.

\section{Discussion}

This study has investigated the incidence of MMR deficiency in a consecutive series of CRC that underwent universal testing by immunohistochemistry from a single Australian pathology practice in Brisbane, Queensland. We found that loss of one or more MMR protein by immunohistochemistry was seen in $19.2 \%$ of cases, with the vast majority being cases with loss of MLH1 and its binding partner PMS2 (89.5\% of all MMR deficient cases). Over $80 \%$ of all cases of MMR deficiency were seen in patients over the age of 70 years, including $57 \%$ of cases with $\mathrm{MSH} 2 / \mathrm{MSH} 6$ loss. As noted in other studies, the majority of MMR-deficient CRC occurred in the proximal colon and were low stage at diagnosis. ${ }^{10}$

This rate of MMR deficiency is higher than the 10-15\% reported in most studies. One possible explanation could be a selection bias in our population. The average annual
CRC incidence at Envoi Specialist Pathologists laboratory between 2012 and 2016 was 415 representing approximately $2.7 \%$ of the 15,151 Australians diagnosed with a CRC in 2011. ${ }^{1}$ From an estimated CRC incidence in Queensland around 3,000 in the same period of time, our population comprises $13.8 \%$ of all newly diagnosed CRC in this state, with a similar median age at diagnosis of 70 years as the one reported for the entire state of Queensland. ${ }^{11}$ The female proportion of $45.5 \%$ in our population was not different from the one in the entire Australian population (44.9\%, $P=0.57$ ). These findings support that our population is representative from the entire Australian population diagnosed with a CRC and argue against a selection from an older population with higher proportion of females who are more likely to develop MMR-deficient CRC with MLH1 methylation. Two population-based studies have data on MMR deficiency in CRC. The Melbourne Collaborative Cohort Study is an Australian prospective cohort study which recruited Melbourne residents from $1990 .^{12}$ In this cohort, the rate of MMRdeficiency was $15 \%$ of 740 incident CRC cases in a population with a mean age of 69 years at diagnosis and a female proportion of $46.2 \% .{ }^{10}$ This lower rate may at least be partially explained by a high proportion (25\%) of individuals recruited in this study born in Mediterranean countries where the proportion of MMR deficiency in CRC has been reported to be $<10 \% .{ }^{13,14}$ In another Australian study from the Royal North Shore Hospital in Sydney, $19.5 \%$ of 1426 CRCs diagnosed between 2004 and 2009 had MMR deficiency, a rate similar to our series. ${ }^{15}$ Possible other causes for the high rate of MMR deficiency in our study include lifestyle factors such as smoking and dietary habits (red meat consumption, cooking practice including barbecuing) that have been reported to be associated with microsatellite instability. ${ }^{16,17}$

Until recently, the recommendation for pathologists was to request MMR protein immunohistochemistry if patients 
bioRxiv preprint doi: https://doi.org/10.1101/270322; this version posted February 23, 2018. The copyright holder for this preprint (which was not certified by peer review) is the author/funder, who has granted bioRxiv a license to display the preprint in perpetuity. It is made available under aCC-BY-NC-ND 4.0 International license.

Universal Testing for Lynch Syndrome

meet the Amsterdam criteria or the revised Bethesda criteria. These clinical criteria include age at CRC diagnosis younger than 50 years and family history of Lynch syndrome-associated malignancies. In practice, pathologists are rarely aware of any delailed family history to apply these criteria when reporting a biopsy or a surgical specimen with CRC. Age at diagnosis was therefore the most common trigger to perform MMR protein immunohistochemistry. In our study, when compared with age restricted testing strategies, 35 of 42 cases (83\%) with a MMR-deficient CRC suggestive of Lynch syndrome (tumours showing MSH2/MSH6 loss, MSH6 loss or PMS2 loss) would have been missed if testing was only performed for patients younger than 50 years at diagnosis. If the age restritction was 70 years, 18 patients (43\%) would have been missed.

There was also a vast increase in the incidence of MLH1 deficiency in patients over 70 years, most of these are likely to be secondary to somatic MLH1 promotor methylation. For CRC with loss of MLH1/PMS2 staining by immunohistochemistry, testing for the somatic BRAF ${ }^{V O 00 E}$ mutation is recommended to help separate sporadic from Lynch syndrome-associated CRC. Mutation testing for $B R A F^{V 600 E}$ is usually offered to patients under the age of 70 as nearly all MLH1-deficient CRC in patients over 70 are caused by MLH1 methylation, not Lynch syndrome. If $B R A F^{V 600 E}$ mutation is detected, the tumour is assumed to be MMR deficient due to MLH1 methylation and no further investigations are performed unless there is a strong clinical suspicion of Lynch syndrome (young age or strong family history suggestive of Lynch syndrome). If BRAF $F^{V 600 E}$ mutation is not detected in the tumour, genetic counselling is recommended with germline testing for a mutation in MLH1, followed by PMS2 if no mutation in MLH1 is found. Prior to germline mutation testing, somatic methylation analysis of the MLH1 gene can be performed to reduce the referral rate for genetic counselling if $M L H 1$ methylation is detected. ${ }^{18}$ Unfortunately, there is currently no Medicare Benefits Schedule (MBS) rebate for BRAF ${ }^{V 600 E}$ mutation testing, MLH1 methylation status or for germline mutation testing in Australia, resulting in a high and increasing rate of unnecessary referral for genetic counselling now that universal testing has become more widely implemented.

Up to $70 \%$ of CRC demonstrating MMR-deficiency suggestive of Lynch syndrome do not have an MMR gene mutation identified by standard genetic testing approaches. $^{19}$ These cases of so called Lynch-like syndrome or suspected Lynch syndrome can be caused by a false abnormal MMR immunostaining result, a hidden germline MMR gene mutation not detected by current sequencing methods, a mutation in other genes causing MMR deficiency, biallelic somatic MMR gene mutation or somatic cell mosaicism. From the two largest studies on Lynch-like cases, $50-70 \%$ of those were caused by biallelic somatic mutation that can be found in any of the $4 \mathrm{MMR}$ genes. ${ }^{20,21}$ Tumour testing for MMR gene mutation is likely to become the next step in the work up of Lynch-like cases to further exclude patients and their relatives from unnecessary Lynch syndrome surveillance.

Beyond screening for Lynch syndrome, MMR protein analysis provides important prognostic and predictive information for the management of CRC patients. MMR deficiency is an established good prognostic factor and predictor to poor response to 5-Fluorouracil therapy. ${ }^{22}$ BRAF mutation is associated with a poor outcome. ${ }^{23}$ The MMR status is also an essential predictor for the response to inhibitors of checkpoint proteins such as PD-1 and PDL1. Patients with an advanced BRAF-mutated $C R C$ will be have a different first-line therapy from those with BRAFwildtype CRC and may now be enrolled in clinical trials using specific BRAF-inhibitors. For all these reasons, MMR protein status along with KRAS, NRAS and BRAF mutation status are now considered as essential components of CRC diagnosis in the new $8^{\text {th }}$ edition of the AJCC Colorectal cancer TNM staging system and are recommended to be tested for by the American Society for Clinical Pathology, College of American Pathologists, Association for Molecular Pathology, and American Society of Clinical Oncology. ${ }^{24}$

This study was limited by the absence of BRAF mutation testing or MLH1 methylation analysis in all cases of MLH1 loss by immunohistochemistry. No germline mutation testing result was available for patients with a MMR deficiency pattern suggestive of Lynch syndrome.

In summary, universal testing for MMR protein deficiency in CRC identifies abnormal patterns of expression suggestive of Lynch syndrome in all age groups, including many in those excluded by current guidelines. Further studies are needed to demonstrate the actual rate of Lynch syndrome individuals identified from this initial screening.

\section{References}

1. Cancer in Australia: an overview, 2014. AIHW (Australian Institute of Health and Welfare) \& AACR (Australasian Association of Cancer Registries): Canberra 2014. Report No. 2. Giardiello FM, Allen JI, Axilbund JE, et al. Guidelines on genetic evaluation and management of Lynch syndrome: a consensus statement by the US Multi-society Task Force on colorectal cancer. Am J Gastroenterol 2014;109:1159-1179.

3. Jenkins MA, Dowty JG, Ait Ouakrim D, et al. Short-term risk of colorectal cancer in individuals with lynch syndrome: a metaanalysis. J Clin Oncol 2015;33:326-331.

4. Moller P, Seppala T, Bernstein I, et al. Cancer incidence and survival in Lynch syndrome patients receiving colonoscopic and gynaecological surveillance: first report from the prospective Lynch syndrome database. Gut 2017;66:464-472.

5. Evaluation of Genomic Applications in P, Prevention Working G. Recommendations from the EGAPP Working Group: genetic testing strategies in newly diagnosed individuals with colorectal cancer aimed at reducing morbidity and mortality from Lynch syndrome in relatives. Genet Med 2009;11:35-41.

6. Stoffel EM, Mangu PB, Gruber SB, et al. Hereditary colorectal cancer syndromes: American Society of Clinical Oncology Clinical Practice Guideline endorsement of the familial riskcolorectal cancer: European Society for Medical Oncology Clinical Practice Guidelines. J Clin Oncol 2015;33:209-217. 7. Syngal S, Brand RE, Church JM, et al. ACG clinical guideline: Genetic testing and management of hereditary gastrointestinal cancer syndromes. Am J Gastroenterol 2015;1 10:223-262.

8. Moreira L, Balaguer F, Lindor N, et al. Identification of Lynch syndrome among patients with colorectal cancer. JAMA 2012;308:1555-1565.

9. Mvundura M, Grosse SD, Hampel H, et al. The costeffectiveness of genetic testing strategies for Lynch syndrome among newly diagnosed patients with colorectal cancer. Genet Med 2010;12:93-104.

10. Buchanan DD, Clendenning M, Rosty C, et al. Tumor testing to identify lynch syndrome in two Australian colorectal cancer cohorts. J Gastroenterol Hepatol 2017;32:427-438. 
bioRxiv preprint doi: https://doi.org/10.1101/270322; this version posted February 23, 2018. The copyright holder for this preprint (which was not certified by peer review) is the author/funder, who has granted bioRxiv a license to display the preprint in perpetuity. It is made available under aCC-BY-NC-ND 4.0 International license.

Universal Testing for Lynch Syndrome

11. Colorectal Cancer in Queensland: An Overview 2012. Queensland Government. Queensland Health: Brisbane 2012. Report No.

12. Giles GG, English DR. The Melbourne Collaborative Cohort Study. IARC Sci Publ 2002;156:69-70.

13. Percesepe A, Borghi F, Menigatti M, et al. Molecular screening for hereditary nonpolyposis colorectal cancer: a prospective, population-based study. J Clin Oncol 2001;19:39443950 .

14. Perez-Carbonell L, Ruiz-Ponte G, Guarinos G, et al. Comparison between universal molecular screening for Lynch syndrome and revised Bethesda guidelines in a large populationbased cohort of patients with colorectal cancer. Gut 2012;61:865872 .

15. Toon CW, Chou A, DeSilva K, et al. BRAFV600E immunohistochemistry in conjunction with mismatch repair status predicts survival in patients with colorectal cancer. Mod Pathol 2014;27:644-650.

16. Slattery ML, Curtin K, Anderson K, et al. Associations between cigarette smoking, lifestyle factors, and microsatellite instability in colon tumors. J Natl Cancer Inst 2000;92:18311836.

17. Wu AH, Shibata D, Yu MC, et al. Dietary heterocyclic amines and microsatellite instability in colon adenocarcinomas. Carcinogenesis 2001;22:1681-1684.

18. Adar T, Rodgers LH, Shannon KM, et al. A tailored approach to BRAF and MLH1 methylation testing in a universal screening program for Lynch syndrome. Mod Pathol 2017;30:440-447.
19. Buchanan DD, Rosty C, Clendenning M, et al. Clinical problems of colorectal cancer and endometrial cancer cases with unknown cause of tumor mismatch repair deficiency (suspected Lynch syndrome). Appl Clin Genet 2014;7:183-193.

20. Haraldsdottir S, Hampel H, Tomsic J, et al. Colon and endometrial cancers with mismatch repair deficiency can arise from somatic, rather than germline, mutations. Gastroenterology 2014;147:1308-1316 e1301.

21. Mensenkamp AR, Vogelaar IP, van Zelst-Stams WA, et al. Somatic mutations in MLH1 and MSH2 are a frequent cause of mismatch-repair deficiency in Lynch syndrome-like tumors. Gastroenterology 2014;146:643-646 e648.

22. Popat S, Hubner R, Houlston RS. Systematic review of microsatellite instability and colorectal cancer prognosis. J Clin Oncol 2005;23:609-618.

23. Lochhead P, Kuchiba A, Imamura Y, et al. Microsatellite Instability and BRAF Mutation Testing in Colorectal Cancer Prognostication. J Natl Cancer Inst 2013;105:1151-1156.

24. Sepulveda AR, Hamilton SR, Allegra CJ, et al. Molecular Biomarkers for the Evaluation of Colorectal Cancer: Guideline From the American Society for Clinical Pathology, College of American Pathologists, Association for Molecular Pathology, and the American Society of Clinical Oncology. J Clin Oncol 2017:JCO2016719807. 